\title{
Aspirin Versus Clopidogrel Monotherapy for the Secondary Prevention of Recurrent Cerebrovascular Attack Following Previous Ischemic Stroke in Patients with Type 2 Diabetes Mellitus: A Systematic Review and Meta-Analysis
}

\author{
Zu-Ye Qin · Xiu-Fang Yang • Chao-Ying Lian · Xun-Jin Yan • \\ Min-Shi Lin · Pravesh Kumar Bundhun · You-Yi Lao \\ Received: February 20, 2020 / Published online: March 27, 2020 \\ (C) The Author(s) 2020
}

\section{ABSTRACT}

Introduction: Type 2 diabetes mellitus (T2DM) and stroke are two different diseases, but have many aspects in common. Aspirin is recommended as an initial treatment for the secondary prevention of recurrent ischemic stroke in patients with T2DM. However, clopidogrel is an oral antiplatelet drug that might be another choice in case of aspirin intolerance. In this analysis, we aimed to systematically compare aspirin versus clopidogrel monotherapy for the secondary prevention of recurrent cerebrovascular attack following previous ischemic stroke in patients with T2DM.

Methods: Online medical databases including Web of Science, MEDLINE, Cochrane central, EMBASE and http://www.ClinicalTrials.com were searched for published articles that satisfied the inclusion and exclusion criteria of this

Digital features To view digital features for this article go to https://doi.org/10.6084/m9.figshare.11968455.

Z.-Y. Qin · X.-F. Yang · C.-Y. Lian · X.-J. Yan ·

M.-S. Lin · Y.-Y. Lao ( $\square)$

Department of Neurology, The First People's

Hospital of Qinzhou, No. 8, Mingyang Road,

Qinzhou 535099, Guangxi Zhuang Autonomous

Region, People's Republic of China

e-mail: qinzuye2008@163.com

P. K. Bundhun

Department of Internal Medicine, Flacq Hospital,

Central Flacq, Mauritius study. Recurrent stroke, fatal stroke, cerebral hemorrhage, myocardial infarction and mortality were considered the main end points in these patients with T2DM. RevMan 5.3 software was used to statistically analyze the data representing each subgroup. Risk ratios (RRs) with 95\% confidence intervals (CIs) were used to represent the results following analysis.

Results: A total of 9218 participants with T2DM who were previously affected by ischemic stroke were included in this analysis, whereby 4917 were assigned to aspirin and 4301 to clopidogrel. This current analysis showed that there was no significant difference in recurrent stroke rate (RR: 0.79, 95\% CI: $0.61-1.02 ; P=0.07)$ observed with aspirin versus clopidogrel in these patients with T2DM. The risk of fatal stroke (RR: $0.88,95 \% \mathrm{CI}$ : $0.39-1.98 ; P=0.76$ ), cerebral hemorrhage (RR: $0.65,95 \%$ CI: $0.38-1.11 ; P=0.12)$, myocardial infarction (RR: 0.88 , 95\% CI: $0.43-1.79$; $P=0.71$ ) and mortality (RR: 1.07, 95\% CI: $0.90-1.27 ; \quad P=0.44) \quad$ were also similarly manifested.

Conclusion: Clopidogrel monotherapy was neither inferior nor superior to aspirin monotherapy for the secondary prevention of recurrent cerebrovascular attack following previous ischemic stroke in patients with T2DM. Hence, clopidogrel or aspirin monotherapy is equally safe and effective in these patients with T2DM. 
Keywords: Aspirin; Cerebrovascular attack; Clopidogrel; Stroke; Type 2 diabetes mellitus

\section{Key Summary Points}

Why carry out this study?

Aspirin is recommended as an initial treatment for the secondary prevention of recurrent ischemic stroke in patients with T2DM

However, clopidogrel might be another choice in case of aspirin intolerence

What was learned from this study?

Clopidogrel monotherapy was neither inferior nor superior to aspirin monotherapy for the secondary prevention of recurrent cerebrovascular attack following previous ischemic stroke in patients with T2DM

Hence, clopidogrel or aspirin monotherapy is equally safe in these patients with T2DM

\section{INTRODUCTION}

Type 2 diabetes mellitus (T2DM) and stroke are two different diseases, but with many aspects in common including dyslipidemia and hypertension [1]. In fact, due to several factors such as platelet hyperactivity [2] and occluded vascular arteries [3], patients with T2DM are more at risk for ischemic stroke [4]. A recent prospective observational study including over 200 acute stroke patients in a city in Southern Iraq showed diabetes mellitus to be associated with a heavier burden for acute stroke with worse outcomes compared with patients without diabetes [1]. In the USA, recurrent stroke contributes up to $25 \%$ of the annual 800,000 strokes cases [5]. The rising rate of stroke in patients with T2DM has led to the development of non-invasive techniques such as cerebrovascular intervention for the management of these cases. Cerebrovascular ultrasonography is nowadays being used to detect stroke and select patients for cerebrovascular intervention [6].

Aspirin is recommended as an initial treatment for the secondary prevention of recurrent ischemic stroke in patients with T2DM [7]. However, clopidogrel is an oral antiplatelet drug that might be another choice in patients with aspirin intolerance.

In this analysis, we aimed to systematically compare aspirin versus clopidogrel monotherapy for the secondary prevention of recurrent cerebrovascular attack following previous ischemic stroke in patients with T2DM.

\section{METHODS}

\section{Data Sources}

Online medical databases including Web of Science, MEDLINE, Cochrane central, EMBASE and http://www.ClinicalTrials.com were searched for published articles that satisfied the inclusion and exclusion criteria of this study. Reference lists of suitable articles were also verified for relevant articles.

\section{Search Terms}

Specific search terms were used during the retrieval of English publications:

- Diabetes mellitus, stroke, aspirin, clopidogrel;

- Diabetes mellitus, stroke, aspirin, clopidogrel, monotherapy;

- Diabetes mellitus, stroke, aspirin monotherapy;

- Diabetes mellitus, stroke, clopidogrel monotherapy;

- Diabetes mellitus, stroke and anticoagulants;

- Diabetes mellitus, ischemic stroke, aspirin;

- Diabetes mellitus, ischemic stroke, clopidogrel;

- Diabetes mellitus, cerebrovascular attack, aspirin;

- Diabetes mellitus, cerebrovascular attack, clopidogrel. 


\section{Criteria for Inclusion}

Studies were included if:

- They compared outcomes in T2DM patients with previous ischemic stroke who were treated with aspirin versus clopidogrel;

- They were randomized trials or observation cohorts (prospective/retrospective);

- They reported clinical outcomes as their end points.

\section{Criteria for Exclusion}

Criteria for exclusion were:

- Studies that did not involve patients with previous ischemic stroke;

- Studies that did not compare aspirin versus clopidogrel monotherapy;

- Studies that were literature reviews/metaanalyses/case studies/letters to editors;

- Duplicated studies.

\section{Data Extraction and Quality Assessment}

Data were carefully extracted by seven authors, including the number of participants with T2DM; the number of participants assigned to aspirin and clopidogrel monotherapy, respectively; the number of T2DM participants with ischemic stroke, recurrent stroke, fatal stroke, cerebral hemorrhage and myocardial infarction; the total number of deaths; the baseline characteristics of the participants; the type of study; and the relevant follow-up time periods.

Any disagreement among the authors was further discussed, and a decision was made by the corresponding author.

The quality assessment for the trials was carried out based on the recommendations by the Cochrane Collaboration [8], and the assessment of the observational studies was carried out by the criteria of the Newcastle-Ottawa Scale (NOS) [9]. Grades were allotted: grade 'A' implied low risk of bias, grade 'B' was moderate risk of bias, and grade ' $\mathrm{C}$ ' was high risk of bias.

\section{Outcomes Reported}

Recurrent cerebrovascular attack was defined as the occurrence of a new stroke in a patient who already had had a previous stroke.

The following outcomes were assessed during a mean follow-up time period between 1 and 5 years:

(1) Recurrent stroke;

(2) Fatal stroke;

(3) Cerebral hemorrhage;

(4) Myocardial infarction (MI);

(5) Mortality.

\section{Statistical Analysis}

RevMan 5.3 software was used to statistically analyze the data representing each subgroup. Heterogeneity was assessed by two methods: the $Q$ statistic test, whereby a $P$ value $\leq 0.05$ was considered statistically significant, and the $I^{2}$ statistic test, whereby heterogeneity increased with a rising $I^{2}$ value. In addition, a fixed statistical model $\left(I^{2}<50 \%\right)$ or a random statistical model $\left(I^{2}>50 \%\right)$ was used based on this $I^{2}$ value. Risk ratios (RRs) with 95\% confidence intervals (CIs) were used to represent the results following analysis.

Sensitivity analysis was carried out by a method of exclusion whereby studies were eliminated one by one, and a new analysis was carried out each time to observe any deviation from the main result.

Publication bias was visually observed through funnel plots.

\section{Compliance with Ethical Guidelines}

This meta-analysis is based on previously conducted studies and does not contain any studies with human participants or animals performed by any of the authors. 


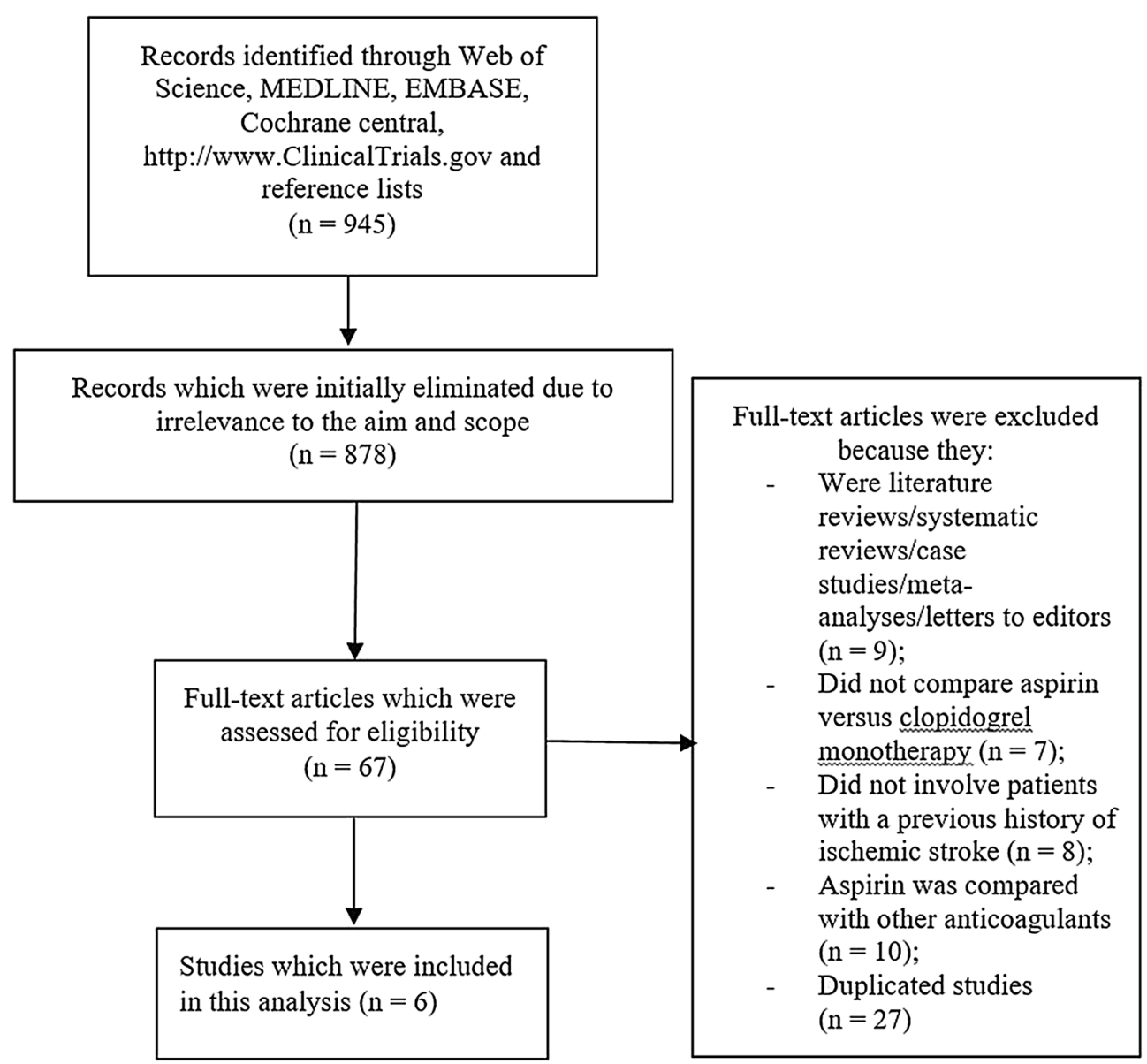

Fig. 1 Flow diagram showing the study selection

\section{RESULTS}

\section{Search Outcomes}

A total of 945 publications were found through the literature search following the PRISMA guideline [10]. The abstracts and titles were carefully assessed by the authors, and an initial elimination was carried out whereby 878 publications were eliminated since they were not linked or related to the scope of the current title of this publication. Sixty-seven (67) full-text articles were assessed for eligibility.

A second set of eliminations was carried out but this time following assessment of the full text articles. This elimination was due to publications that:
- Were literature reviews, systematic reviews, meta-analyses, case studies and letters to editors (9);

- Did not compare aspirin versus clopidogrel monotherapy (7);

- Did not involve patients with a history of previous ischemic stroke (8);

- Aspirin was compared with other antiplatelet monotherapy such as cilostazol (10);

- Duplicated studies (27).

Finally, only six studies [11-16] were selected for this analysis (Fig. 1) (Table 1).

\section{Study Features (General)}

A total of 9218 participants with T2DM who were previously affected by ischemic stroke were included in this analysis, whereby 4917 
Table 1 Types of participants, outcomes and follow-up time periods

\begin{tabular}{|c|c|c|c|}
\hline Studies & Types of participants & Outcomes & $\begin{array}{l}\text { Mean follow-up } \\
\text { time period }\end{array}$ \\
\hline Caprie 1996 [11] & $\begin{array}{l}\text { T2DM with previous } \\
\text { ischemic stroke }\end{array}$ & $\begin{array}{l}\text { Non-fatal recurrent stroke, fatal recurrent } \\
\text { stroke, non-fatal and fatal MI, death }\end{array}$ & 1.91 years \\
\hline Chi 2018 [12] & $\begin{array}{l}\text { T2DM with previous } \\
\text { ischemic stroke }\end{array}$ & Recurrent stroke, death & 1 year \\
\hline Christiansen 2015 [13] & $\begin{array}{l}\text { T2DM with previous } \\
\text { ischemic stroke }\end{array}$ & $\begin{array}{l}\text { Recurrent ischemic stroke, risk of } \\
\text { cerebrovascular bleeding }\end{array}$ & 1 year \\
\hline Ge 2019 [14] & $\begin{array}{l}\text { T2DM with previous } \\
\text { ischemic stroke }\end{array}$ & $\begin{array}{l}\text { Cerebral micro-bleeding, macroscopic } \\
\text { bleeding }\end{array}$ & 5 years \\
\hline Lee 2014 [15] & $\begin{array}{l}\text { T2DM with previous } \\
\text { ischemic stroke }\end{array}$ & $\begin{array}{l}\text { Recurrent stroke, ischemic stroke, } \\
\text { intracranial hemorrhage, fatal stroke, } \\
\text { MI, mortality }\end{array}$ & 1 year \\
\hline Milionis 2017 [16] & $\begin{array}{l}\text { T2DM with previous } \\
\text { ischemic stroke }\end{array}$ & Mortality, recurrent stroke & 6 years \\
\hline
\end{tabular}

T2DM type 2 diabetes mellitus, $M I$ myocardial infarction

Table 2 Main features of the studies included in this meta-analysis

\begin{tabular}{|c|c|c|c|c|c|}
\hline Studies & $\begin{array}{l}\text { Type of } \\
\text { study }\end{array}$ & $\begin{array}{l}\text { Bias risk grade } \\
\text { following } \\
\text { assessment }\end{array}$ & $\begin{array}{l}\text { Participants on } \\
\text { ASA monotherapy } \\
(n)\end{array}$ & $\begin{array}{l}\text { Participants on } \\
\text { clopidogrel } \\
\text { monotherapy }(n)\end{array}$ & $\begin{array}{l}\text { Total no. of } \\
\text { participants } \\
(n)\end{array}$ \\
\hline Caprie1996 & $\begin{array}{l}\text { Randomized } \\
\text { trial }\end{array}$ & B & 831 & 808 & 1639 \\
\hline Chi2018 & OS & B & 2724 & 2713 & 5437 \\
\hline Christiansen 2015 & Cohort study & B & 380 & 455 & 835 \\
\hline Ge2019 & $\begin{array}{l}\text { Retrospective } \\
\text { study }\end{array}$ & B & 49 & 49 & 98 \\
\hline Lee2014 & Cohort study & B & 736 & 169 & 905 \\
\hline Milionis2017 & $\begin{array}{l}\text { Retrospective } \\
\text { study }\end{array}$ & B & 197 & 107 & 304 \\
\hline $\begin{array}{l}\text { Total no. of } \\
\text { participants }(n)\end{array}$ & - & - & 4917 & 4301 & 9218 \\
\hline
\end{tabular}

$O S$ observational study, $A S A$ aspirin

were assigned to aspirin and 4301 to clopidogrel, as shown in Table 2.

A methodologic assessment was carried out on the studies. Grade 'B' was allotted to each of the studies showing moderate risk of bias.

\section{Baseline Features of the Participants}

Table 3 lists the baseline features of the T2DM participants with previous ischemic stroke. Male participants who were on aspirin varied 
Table 3 Baseline features of the participants with type 2 diabetes mellitus

\begin{tabular}{llllll}
\hline Studies & $\begin{array}{l}\text { Males (\%) } \\
\text { ASA/Clo }\end{array}$ & $\begin{array}{l}\text { Age (years) } \\
\text { ASA/Clo }\end{array}$ & $\begin{array}{l}\text { HBP (\%) } \\
\text { ASA/Clo }\end{array}$ & $\begin{array}{l}\text { DYS (\%) } \\
\text { ASA/Clo }\end{array}$ & $\begin{array}{l}\text { CS (\%) } \\
\text { ASA/Clo }\end{array}$ \\
\hline Caprie1996 & $63.0 / 64.0$ & $64.7 / 64.5$ & $65.0 / 65.0$ & $38.0 / 37.0$ & $22.0 / 22.0$ \\
Chi2018 & $60.2 / 60.5$ & $71.8 / 71.4$ & $79.2 / 78.6$ & $45.0 / 45.9$ & $33.3 / 34.4$ \\
Christiansen2015 & $47.5 / 49.3$ & $75.3 / 68.6$ & $43.2 / 42.3$ & - & - \\
Ge2019 & $57.0 / 54.0$ & $65.4 / 64.3$ & $57.0 / 53.0$ & $46.0 / 43.0$ & $46.0 / 42.0$ \\
Lee2014 & $59.7 / 59.6$ & $71.1 / 70.8$ & $52.0 / 57.3$ & $21.8 / 20.3$ & - \\
Milionis2017 & $66.5 / 74.8$ & - & $76.6 / 72.0$ & $51.8 / 59.8$ & - \\
\hline
\end{tabular}

$A S A$ aspirin, Clo clopidogrel, HBP high blood pressure, DYS dyslipidemia, $C S$ current smoker

from $47.5 \%$ to $66.5 \%$, whereas male patients who were on clopidogrel varied from $49.3 \%$ to $74.8 \%$. Mean age of the participants varied between 64.3 and 75.3 years; $42.3 \%$ to $79.2 \%$ of the participants were hypertensive, $20.3 \%$ to $59.8 \%$ of the participants suffered from dyslipidemia, and $22.0 \%$ to $46.0 \%$ of the participants were current smokers.

\section{Main Results of this Analysis}

This current analysis showed that there was no significant difference in recurrent stroke (RR:
$0.79,95 \%$ CI: 0.61-1.02; $P=0.07)$ observed with aspirin versus clopidogrel monotherapy for the secondary prevention of recurrent cerebrovascular attack following previous ischemic stroke in patients with T2DM as shown in Fig. 2. Our analysis also showed that the risk of fatal stroke (RR: $0.88,95 \%$ CI: 0.39-1.98; $P=0.76$ ), cerebral hemorrhage (RR: $0.65,95 \%$ CI: 0.38-1.11; $P=0.12$ ), MI (RR: $0.88,95 \% \mathrm{CI}$ : 0.43-1.79; $P=0.71$ ) and mortality (RR: 1.07, 95\% CI: $0.90-1.27 ; P=0.44)$ were also similar with aspirin versus clopidogrel monotherapy in these patients with T2DM as shown in Fig. 3.

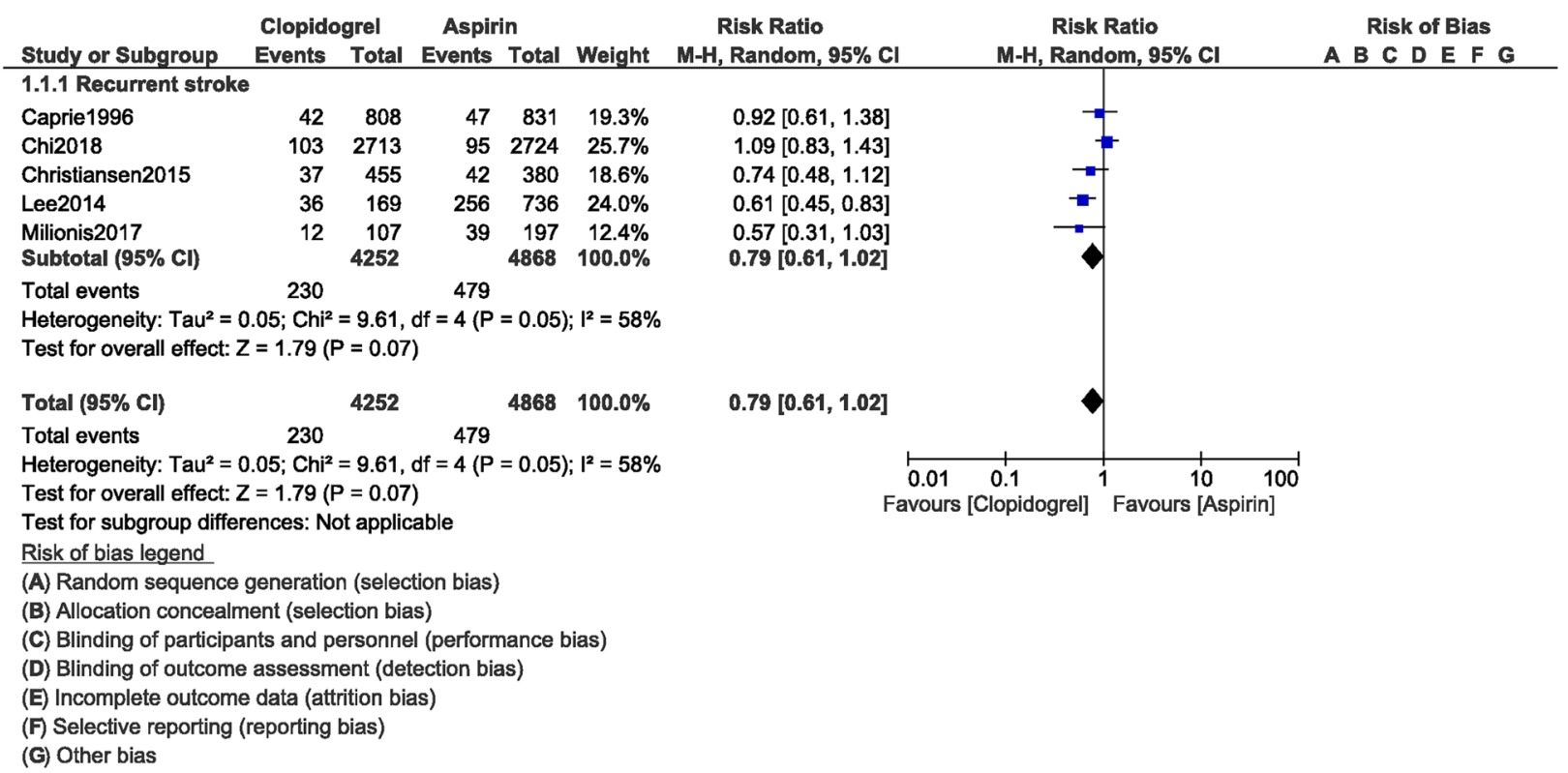

Fig. 2 Recurrent stroke observed in T2DM patients on aspirin versus clopidogrel monotherapy 


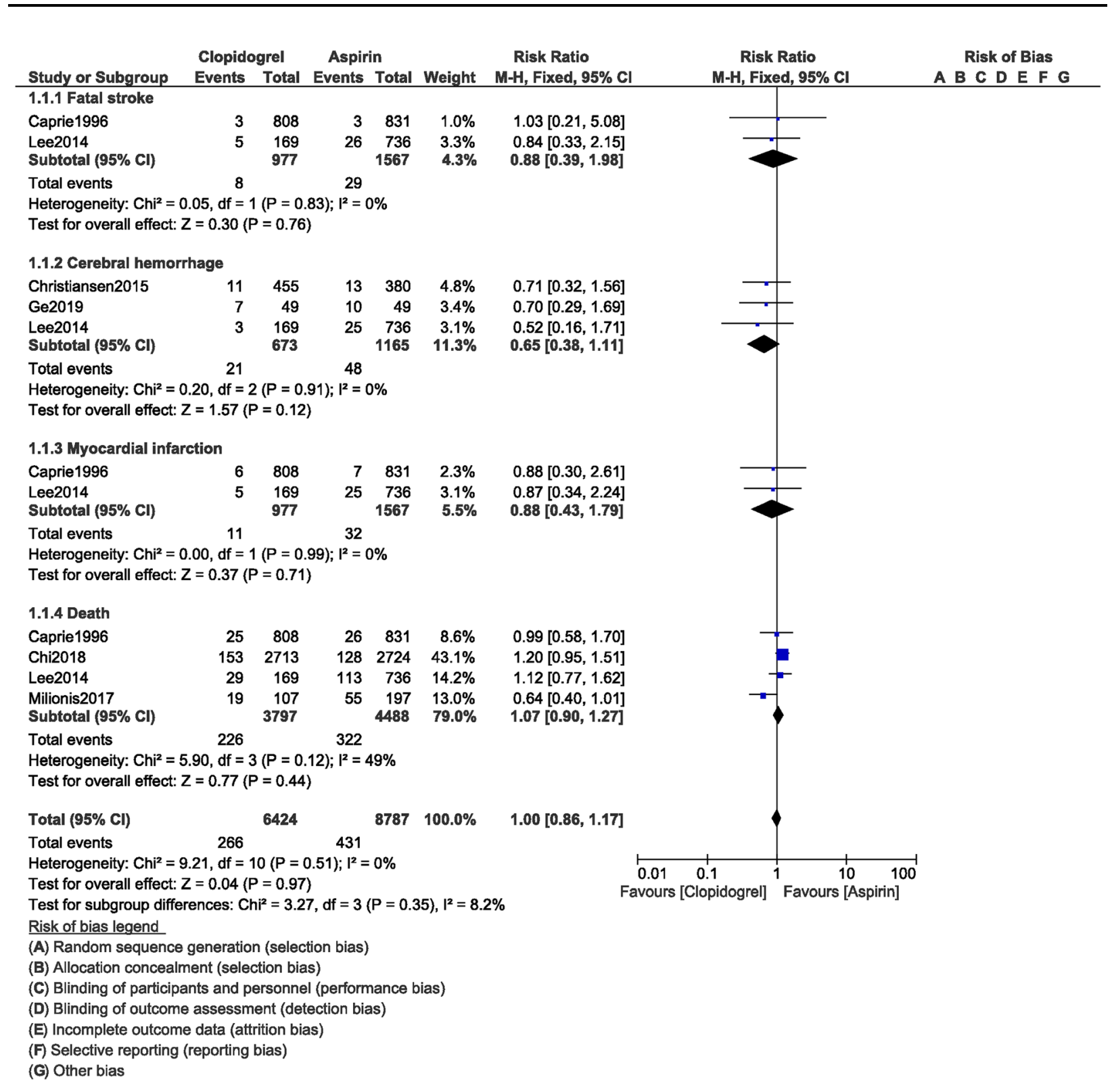

Fig. 3 Other clinical outcomes observed in T2DM patients on aspirin versus clopidogrel monotherapy

The results have been summarized in Table 4.

Consistent results were obtained throughout when sensitivity analysis was carried out.

Visual assessment of the funnel plot also showed minimal evidence of publication bias across the studies that were involved in assessing the cerebrovascular and other clinical outcomes among these patients with T2DM as shown in Fig. 4.

\section{DISCUSSION}

This current analysis showed that in patients with T2DM, aspirin or clopidogrel monotherapy was equally effective and safe for the secondary prevention of recurrent cerebrovascular attack following previous ischemic stroke. There was no significant difference in recurrent stroke, fatal stroke, cerebral hemorrhage, myocardial infarction and mortality when either aspirin or 
Table 4 Summarizing the results of this analysis involving participants with T2DM previously affected by stroke

\begin{tabular}{llll}
\hline Outcomes & RR with 95\% CI & P value & $\boldsymbol{I}^{\mathbf{2}}$ value (\%) \\
\hline Recurrent stroke & $0.79[0.61-1.02]$ & 0.07 & 58 \\
Fatal stroke & $0.88[0.39-1.98]$ & 0.76 & 0 \\
Cerebral hemorrhage & $0.65[0.38-1.11]$ & 0.12 & 0 \\
Myocardial infarction & $0.88[0.43-1.79]$ & 0.71 & 0 \\
Death & $1.07[0.90-1.27]$ & 0.44 & 49 \\
\hline
\end{tabular}

$R R s$ risk ratios, CIs confidence intervals

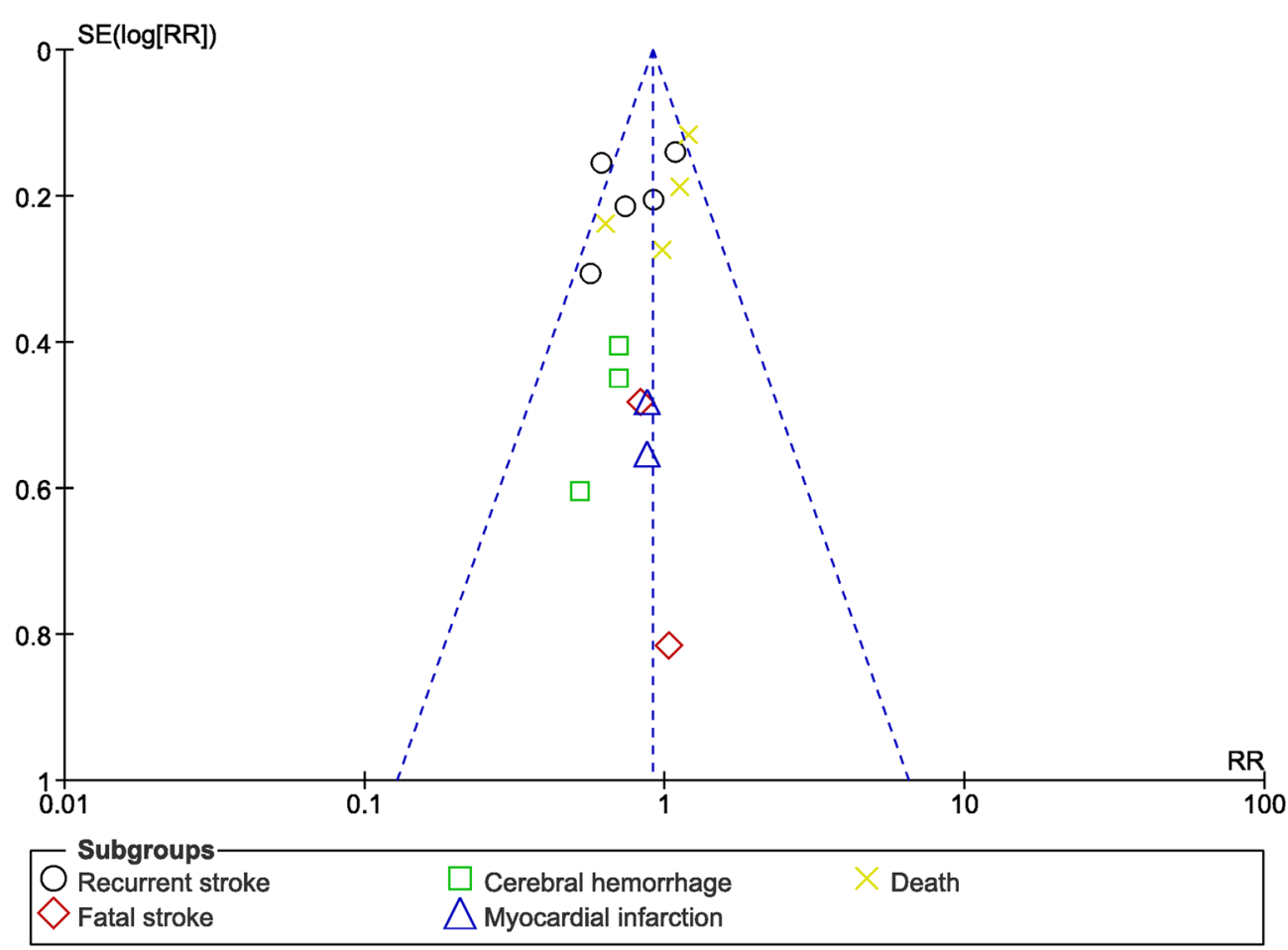

Fig. 4 Funnel plot representing publication bias

clopidogrel monotherapy was used in these patients with T2DM.

The Study of Cardiovascular Events in Diabetes (ASCEND) randomized trial demonstrated that aspirin monotherapy in patients with T2DM could prevent serious vascular events [17]. Among the 15,480 participants, serious vascular events occurred more in the placebo compared with the aspirin group. However, major bleeding was also observed with the use of aspirin in these patients compared with those who did not use antiplatelet medications.

Apart from clopidogrel, aspirin monotherapy has also been compared with other anticoagulants in patients with recurrent stroke. For example, in the Prevention of cerebrovascular and cardiovascular Events of ischemic origin with the TP receptor antagonist teRutroban in patients with a history of ischemic strOke or tRansient ischeMic attack (PERFORM) study, 
the baseline features of the population were described [7].

Ten-year survival data from the Athens Stroke Outcome Project [16] showed clopidogrel monotherapy to be more favorable compared with aspirin monotherapy for the prevention of recurrent stroke in patients with T2DM. Among 197 participants with T2DM who were treated by aspirin and 107 participants who were treated with clopidogrel, recurrent stroke occurred only in $11.2 \%$ of the participants, whereas $19.7 \%$ of the participants on aspirin suffered recurrent stroke.

Antiplatelet drugs in patients with T2DM and in patients with T2DM who have undergone cerebrovascular intervention are vital in this era. Further research should be carried out on this aspect to have a better choice of antiplatelet agent in such patients without any increased risk of bleeding.

\section{Limitations}

Several limitations were observed in this study. First, the total number of participants might not be sufficiently large to draw a strong and powerful conclusion. The total number of studies selected for this analysis was limited since there have seldom been research articles based on aspirin versus clopidogrel monotherapy in T2DM participants with previous cerebrovascular attack. Hence, subgroups assessing fatal stroke and MI involved only two studies. The other studies did not report these two outcomes and hence could not be included during subgroup analyses for these specific outcomes. Several other important outcomes and adverse drug events including gastrointestinal bleeding, abdominal pain, melena and other bleeding tendencies could not be assessed since they were not reported in the original studies. Moreover, another limitation of this analysis might be the fact that data from randomized trials and observational studies were combined and analyzed. This might have affected the result of this analysis. However, the total number of studies were limited, and separating randomized trials and observational cohorts and carrying out an analysis would not have been possible.

\section{CONCLUSIONS}

Clopidogrel monotherapy was neither inferior nor superior to aspirin monotherapy for the secondary prevention of recurrent cerebrovascular attack following previous ischemic stroke in patients with T2DM. Hence, clopidogrel or aspirin monotherapy is equally safe and effective in these patients with T2DM.

\section{ACKNOWLEDGEMENTS}

Funding. No funding or sponsorship was received for this study or publication of this article.

Authorship. All named authors meet the International Committee of Medical Journal Editors (ICMJE) criteria for authorship for this article, take responsibility for the integrity of the work as a whole, and have given their approval for this version to be published.

Authorship Contributions. Dr. Zu-Ye Qin, Dr. Xiu-Fang Yang, Dr. Chao-Ying Liang, Dr. Xun-Jin Yan, Dr. Min-Shi Lin, Dr. Pravesh Kumar Bundhun and Dr. You-Yi Lao were responsible for the conception and design, acquisition of data, analysis and interpretation of data, drafting the initial manuscript and revising it critically for important intellectual content. Dr. Zu-Ye Qin and Dr. Xiu-Fang Yang wrote the final draft of the manuscript. Zu-Ye Qin and Xiu-Fang Yang contributed equally to this study, and they are co-first authors. All the authors approved the final manuscript as it is.

Disclosures. Zu-Ye Qin, Xiu-Fang Yang, Chao-Ying Lian, Xun-Jin Yan, Min-Shi Lin, Pravesh Kumar Bundhun and You-Yi Lao have nothing to disclose.

Compliance with Ethics Guidelines. This meta-analysis is based on previously conducted 
studies and does not contain any studies with human participants or animals performed by any of the authors.

Data Availability. All data generated or analyzed during this study are included in this published article.

Open Access. This article is licensed under a Creative Commons Attribution-NonCommercial 4.0 International License, which permits any non-commercial use, sharing, adaptation, distribution and reproduction in any medium or format, as long as you give appropriate credit to the original author(s) and the source, provide a link to the Creative Commons licence, and indicate if changes were made. The images or other third party material in this article are included in the article's Creative Commons licence, unless indicated otherwise in a credit line to the material. If material is not included in the article's Creative Commons licence and your intended use is not permitted by statutory regulation or exceeds the permitted use, you will need to obtain permission directly from the copyright holder.To view a copy of this licence, visit http:// creativecommons.org/licenses/by-nc/4.0/.

\section{REFERENCES}

1. Chen R, Ovbiagele B, Feng W. Diabetes and stroke: epidemiology, pathophysiology, pharmaceuticals and outcomes. Am J Med Sci. 2016;351(4):380-6.

2. Kaur R, Kaur M, Singh J. Endothelial dysfunction and platelet hyperactivity in type 2 diabetes mellitus: molecular insights and therapeutic strategies. Cardiovasc Diabetol. 2018;17(1):121.

3. Dyet JF, Nicholson AA, Ettles DF. Vascular imaging and intervention in peripheral arteries in the diabetic patient. Diabetes Metab Res Rev. 2000;16 Suppl 1:S16-22.

4. Ye G, Gao Q, Qi P, Wang J, Hu S, Chen K, Tan T, Lu $\mathrm{J}$, Wang D. The role of diabetes mellitus on the thrombus composition in patients with acute ischemic stroke. Interv Neuroradiol. 2020;10: 1591019919896940.
5. Oza R, Rundell K, Garcellano M. Recurrent ischemic stroke: strategies for prevention. Am Fam Phys. 2017;96(7):436-40.

6. Sharma VK, Yohanna K, Kawnayn G, Sarkar N, Batra A. Cerebrovascular ultrasonography for selecting patients for stroke intervention. Recent Pat CNS Drug Discov. 2013;8(3):205-19.

7. Bousser MG, Amarenco P, Chamorro A, Fisher M, Ford I, Fox K, Hennerici M, Mattle HP, Rothwell PM; PERFORM Study Investigators. The Prevention of cerebrovascular and cardiovascular Events of ischemic origin with teRutroban in patients with a history of ischemic strOke or tRansient ischeMic attack (PERFORM) study: baseline characteristics of the population. Cerebrovasc Dis. 2009;27(6): 608-13.

8. Higgins JP, Altman DG, Gøtzsche PC, Jüni P, Moher $\mathrm{D}$, Oxman $\mathrm{AD}$, Savovic J, Schulz KF, Weeks L, Sterne JA; Cochrane Bias Methods Group; Cochrane Statistical Methods Group. The Cochrane Collaboration's tool for assessing risk of bias in randomised trials. BMJ. 2011;343:d5928.

9. Stang A. Critical evaluation of the Newcastle-Ottawa scale for the assessment of the quality of nonrandomized studies in meta-analyses. Eur J Epidemiol. 2010;25(9):603-5.

10. Liberati A, Altman DG, Tetzlaff J, Mulrow C, Gøtzsche PC, Ioannidis JP, Clarke M, Devereaux PJ, Kleijnen J, Moher D. The PRISMA statement for reporting systematic reviews and meta-analyses of studies that evaluate healthcare interventions: explanation and elaboration. BMJ. 2009;21(339): b2700.

11. CAPRIE Steering Committee. A randomised, blinded, trial of clopidogrel versus aspirin in patients at risk of ischaemic events (CAPRIE). CAPRIE Steering Committee. Lancet. 1996;348(9038):1329-39.

12. Chi NF, Wen CP, Liu CH, Li JY, Jeng JS, et al. Comparison between aspirin and clopidogrel in secondary stroke prevention based on real-world data. J Am Heart Assoc. 2018;7(19):e009856.

13. Christiansen CB, Pallisgaard J, Gerds TA, Olesen JB, et al. Comparison of antiplatelet regimens in secondary stroke prevention: a nationwide cohort study. BMC Neurol. 2015;2(15):225.

14. Ge L, Ouyang X, Ban C, Yu H, Wu Q, Wu H, Liang J. Cerebral microbleeds in patients with ischemic cerebrovascular disease taking aspirin or clopidogrel. Medicine (Baltimore). 2019;98(9):e14685.

15. Lee M, Wu YL, Saver JL, Lee HC, Lee JD, Chang KC, Wu CY, Lee TH, Wang HH, Rao NM, Ovbiagele B. Is clopidogrel better than aspirin following 
breakthrough strokes while on aspirin? A retrospective cohort study. BMJ Open. 2014;4(12): $\mathrm{e} 006672$.

16. Milionis H, Ntaios G, Papavasileiou V, Spengos K, Manios E, Elisaf M, Vemmos K. Aspirin versus clopidogrel for type 2 diabetic patients with firstever noncardioembolic acute ischemic stroke: tenyear survival data from the Athens stroke outcome project. J Stroke Cerebrovasc Dis. 2017;26(12): 2769-77.
17. ASCEND Study Collaborative Group, Bowman L, Mafham M, Wallendszus K, Stevens W, Buck G, Barton J, Murphy K, Aung T, Haynes R, Cox J, Murawska A, Young A, Lay M, Chen F, Sammons E, Waters E, Adler A, Bodansky J, Farmer A, McPherson R, Neil A, Simpson D, Peto R, Baigent C, Collins R, Parish S, Armitage J. Effects of aspirin for primary prevention in persons with diabetes mellitus. N Engl J Med. 2018;379(16):1529-39. 